\title{
Teaching Reform of Computer Application Basis Based on Blended Learning
}

\author{
Liangtao Yang \\ Engineering Training Center \\ Shanghai Polytechnic University \\ Shanghai, China \\ ltyang@sspu.edu.cn
}

\begin{abstract}
Blended learning is an organic combination of online learning and traditional face-to-face classroom learning, and it is one of the research hotspots and important development directions of university teaching reform. On the basis of sorting out and analyzing the current situation of computer application basic course teaching in our university, this paper constructs a task-based blended learning model, and carries out teaching practice based on this model with the help of online course platform of computer application basic. Finally, the article takes the learners of the course as the object of investigation and makes a brief analysis of the teaching effect of the model.
\end{abstract}

Keywords—blended learning; task-driven; online course; teaching reform

\section{INTRODUCTION}

The rapid development of Internet technology and mobile communication technology has expanded people's learning time and space. The combination of information technology and traditional classroom teaching provides a new opportunity for the reform of higher education, and it is one of the research hotspots and important development directions of higher education reform.[1]

The construction of online education resources in our university has experienced the earliest construction of network courses, then the introduction of the Curriculum Center of Shanghai Polytechnic University, and now the construction of online courses. The purpose of online course construction is to explore the reform of education and teaching, improve the level of education and teaching and the quality of personnel training. [2]Some courses are never used after they are completed, or only use the most basic functions such as news release, resource download and homework submission. The frequency and efficiency of students' learning by using online educational resources and their recognition of online educational resources are seldom or never concerned. How to effectively apply online education resources is a difficult problem for the teachers in universities.[3]

Blended learning is a new form of teaching guided by the theory of blended learning and with information technology as an important means. Blended learning injects more technical elements and learning resources, which enables learners to realize online learning through smartphone terminals. It really realizes learning at anytime and anywhere according to their individual needs, and makes up for the shortcomings of face-to-face classroom teaching that cannot achieve "teaching according to aptitude, educating according to aptitude". There are many problems in the teaching of "Computer Application Foundation" course in our university, such as more content, less class hours, more people and less interaction. Blended learning mode is more suitable for the new generation of students. [4]They have a stronger desire for instant messaging technology, collaborative learning and online learning environment. The emergence of blended learning provides new possibilities for solving these problems.

\section{BACKGROUND OF TEACHING REFORM}

Information science and information technology with computer, network communication and multimedia as the core have completely changed people's work, study and life style. Mastering the preliminary knowledge and application ability of modern information technology is the essential basic quality of modern college students. "Computer Application Foundation" is the first basic computer course for non-computer majors. This course comprehensively introduces the basic knowledge of computer, basic operation and the use of common software. It includes the basic structure and working principle of computer, the use of office software, multimedia technology, computer network and image processing software. Through the teaching of this course, students can master the preliminary knowledge and application ability of modern information technology, improve the practical ability of using application software to solve practical problems, and lay a foundation for future application of computer knowledge and skills to solve practical problems of this major.

In order to meet the needs of the reform and development of higher education, and in accordance with the school's orientation of "vocational-oriented higher education", our university began to implement the full-time credit system from the full-time undergraduate and higher vocational students of grade 2015. After the reform of the credit system, the basic course of computer application has changed from a public compulsory course to a public elective course. The course has changed from 64 hours to 32 hours. The course involves up to four application software (Photoshop, Word, PowerPoint, and Excel). Because the students did not learn this software in high school, they could not learn the above in 32 hours. How to solve the above practical teaching problems? Blended learning 
combines the advantages of traditional classroom teaching and digital teaching. The complementary advantages of the two can effectively expand the time and space of learning, make learning everywhere and everywhere, so as to achieve better teaching effect.

\section{CONSTRUCTING A TASK-BASED BLENDED LEARNING MODEL}

Face-to-face classroom teaching is still the main teaching mode of school education, which is conducive to giving full play to the leading role of teachers. However, it overemphasizes uniformity and neglects students' personality characteristics. The time and place of online learning are relatively flexible, but there are high requirements for learners' autonomous learning ability. [5]Blended learning combines the advantages of both, can give full play to the leading role of teachers and students' autonomous learning ability, and can make full use of the learning environment constructed by network and multimedia technology, teaching resources are more abundant, knowledge acquisition is more convenient, and teacher-student exchanges are more diverse.
Task-driven teaching refers to integrating the concepts, principles and skills of subject knowledge into each learning task according to the teaching objectives, around the teaching content and in accordance with the principle of gradual progress, so as to focus on the orientation of the teaching content, make students clear what to do, and take task completion and problem solving as the main teaching activities throughout the whole teaching process. The essence of task-driven teaching is to induce learners' learning motivation through "task" and create learning conditions and environments for self-exploration, discovery and innovation. Therefore, task-driven teaching is suitable for students' learning characteristics in general undergraduate. [6]

In order to make full use of the online courses, meet the needs of the reform of basic computer courses in universities, and make up for the uneven computer level of students, based on the in-depth analysis of blended learning theory and task-driven teaching, the author constructs a task-based blended learning model, the above figure is the learning flow chart of the learning model.

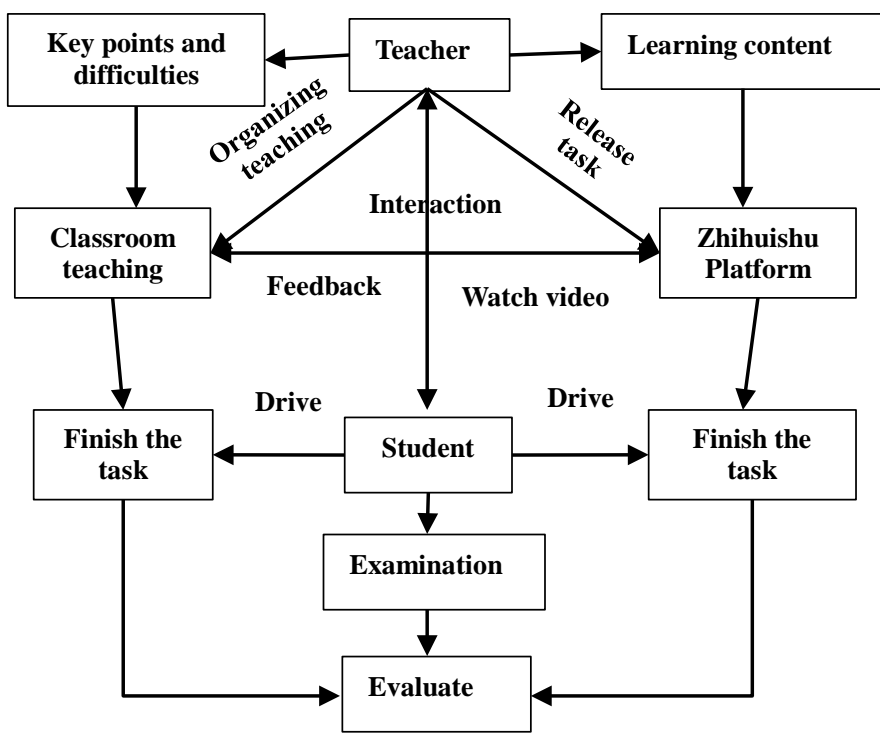

Fig. 1 The learning flow chart of the learning mode

In order to ensure the smooth implementation of the learning process, we divide the teaching content into several teaching units according to the teaching objectives, and each teaching unit is divided into three parts: pre-class, in-class and after-class. The following sections introduce the learning process.

\section{A. Watching Knowledge Points Teaching Video before Class}

For teachers, in order to enable students to understand the main knowledge points of each class, teachers need to prepare detailed curriculum learning task sheets beforehand. The task list includes two parts: one is the teaching video of knowledge points that students need to watch, and the other is the exercise tasks related to knowledge points. Task sheet is the support of students' autonomous learning, which can better guide students to learn according to the teaching objectives. For students, they need to watch the teaching videos of knowledge points independently on the SPOC learning platform and explore knowledge according to their learning tasks. In the process of self-study, if problems or doubts are found, teachers and students can communicate through instant messaging tools. After the end of autonomous learning, students need to know what needs to be strengthened, and what still has doubts to be answered by teachers. At the same time, students should summarize the existing problems, which are not only conducive to students' understanding of knowledge, but also conducive to teachers to better grasp the students' learning situation, so as to teach students in accordance with their aptitude.

\section{B. Solving the key and difficult points and completing the task in class}

Classroom teaching is the stage of knowledge construction of this learning model. The purpose is to enable students to master knowledge completely, cultivate students' innovative thinking and ability to solve problems independently, and 
provide a complete learning experience. In the classroom, we divide a lesson into two stages: the first stage is knowledge review, discussing the key points and difficulties, and clearing up the knowledge points of self-study online. The second stage includes the assignment of tasks by teachers and the completion of tasks by students. Task as the main line, so that students master knowledge in the completion of tasks, improve the ability to analyze and solve problems. For teachers, first of all, we should understand the problems that students encounter in learning and what knowledge points are difficult to grasp. We should spend less time before the beginning of the class to explain the problems encountered in pre-class learning, so as to ensure that most students can understand and master the content of this section. For students, when teachers review the key and difficult points of knowledge, they should follow the teacher's train of thought and review the problems they encounter in their pre-class learning. When talking about places you don't understand, you should listen carefully, consult the teacher actively.

\section{Checking the missing points and consolidating knowledge after class}

After class is the knowledge consolidation stage of this learning mode. In task-based blended learning, teachers will summarize and sort out the knowledge points that students have not mastered according to their task completion, and then upload them to the SPOC learning platform for students to review and consolidate. At the same time, students can log on to SPOC platform to view the summarized knowledge points and modify and improve the test questions. When you encounter difficulties, you can consult in the online discussion module of SPOC platform for targeted guidance. Through active exchanges and discussions with students, thinking collision, and constantly improve the understanding and mastery of knowledge.

\section{TEACHING PRACTICE AND EFFECTIVENESS EVALUATION}

\section{A. Teaching Practice}

In order to strengthen professional construction and educational reform, and improve the level of education and teaching and the quality of personnel training, our university will set up projects to support about 20 online courses every year. "Computer Application Basis" online course project was established in 2018. After a semester of intense and orderly preparation, the online course of "Computer Application Basis" has been launched and put into use on the zhihuishu Online Education Platform (http://www.zhihuishu.com) in the autumn of 2018-2019. There are four chapters in the online course, which correspond to four application software: WORD, EXCEL, POWERPOINT and PHOTOSHOP. There are 37 teaching videos, each of which lasts about 13 minutes and 8 hours in all. In addition to teaching videos, there are abundant course materials in the platform, including explanatory materials of knowledge points teaching videos and test questions of each chapter, four sets of test questions for each chapter, a total of sixteen sets. The explanatory material of knowledge points is used for students to practice the operation of teaching videos so as to deepen the learning of knowledge points. Chapter test is used for students to test and consolidate their knowledge after completing the learning of knowledge points in this chapter.

170 students from different majors in the first grade of Shanghai Polytechnic University were selected to form three elective classes, and the task-based blended learning model was adopted to study the course of Computer Application Foundation. After the completion of the course selection, the list of students will be imported into the zhihuishu Platform according to the selected class, which can be used for students to $\log$ in and register on zhihuishu Platform. Because it is a new way of learning, students have not been exposed before, so the first class needs to introduce the task-based blended learning model to students, including student registration, video viewing, homework submission, course materials use and course assessment. Because the list of students has been imported into the platform beforehand, students only need to enter their student number and default password to login to the platform to confirm the course. They can login in two ways, one is to download "zhidao" APP login using mobile phones, the other is to login using PC to enter the website. Knowledge Points Teaching Video can be watched by students on mobile phones or on PCs. In the process of watching, students can operate with computers. Completing chapter testing tasks and submitting assignments can only be done on PC. The course assessment consists of three parts: 20 points for watching videos, 20 points for chapter tests and 60 points for final examinations.

\section{B. Teaching Effect and Enlightenment}

In teaching practice, students are enthusiastic about learning, there is a good interaction between teachers and students, students can basically watch teaching videos and submit assignments according to the requirements of teachers, and the final exam results are also ideal. In order to understand students' recognition of Task-based blended learning model and their learning situation, at the end of this course, we conducted an anonymous questionnaire survey on students by using questionnaires stars. Four dimensions of the questionnaire were designed to collect information. The following is an analysis of the results of the questionnaire survey.

TABLE I. IDENTITY OF TASK-BASED BLENDED LEARNING MODEL

What do you think of the blended learning model in this course?

\begin{tabular}{|l|c|c|c|}
\multicolumn{1}{c}{ Option } & Subtotal & \multicolumn{2}{c|}{ Proportion } \\
\hline Like it very much & 81 & & $49.09 \%$ \\
\hline Prefer & 53 & & $32.12 \%$ \\
\hline commonly & 21 & & $12.73 \%$ \\
\hline Dislike & 4 & & $2.42 \%$ \\
\hline Very disliked & 6 & & $3.64 \%$ \\
\hline Effective number & 165 & & \\
\hline
\end{tabular}

Table I analyses the results of the questionnaire. Among 165 questionnaires, 81 people were very fond of the learning mode, accounting for nearly $50 \%$ of the total number of students. There were 155 students who answered that they liked the learning mode, with a point ratio of $94 \%$, and only 10 students who did not like the learning mode, accounting for 
$6 \%$. It shows that the learning mode is popular with students and they are willing to try it.

TABLE II. THE INFLUENCE OF THIS MODE ON LEARNING THE COURSE OF COMPUTER APPLICATION BASIS

Do you think that blended learning promotes your study of Computer Application Foundation?

\begin{tabular}{|l|c|c|c|}
\hline \multicolumn{1}{c}{ Option } & Subtotal & \multicolumn{2}{c|}{ Proportion } \\
\hline $\begin{array}{l}\text { Totally } \\
\text { ineffective. }\end{array}$ & 8 & & $4.85 \%$ \\
\hline seldom effective & 19 & & $11.52 \%$ \\
\hline $\begin{array}{l}\text { Basically } \\
\text { effective }\end{array}$ & 39 & & $23.64 \%$ \\
\hline Effective & 54 & & $32.73 \%$ \\
\hline Very effective & 45 & & $27.27 \%$ \\
\hline Effective number & 165 & & \\
\hline
\end{tabular}

Table II is an analysis of the impact of this model on the learning of the course "Computer Application Basis". Among 165 questionnaires, 138 respondents were very effective, effective and basically effective, with a point-to-point ratio of $84 \%$; 27 respondents were seldom effective and totally ineffective, accounting for $16 \%$. It indicates that the learning mode can stimulate students' enthusiasm for learning and promote the learning of the curriculum.

TABLE III. ADVANTAGES OF BLENDED LEARNING

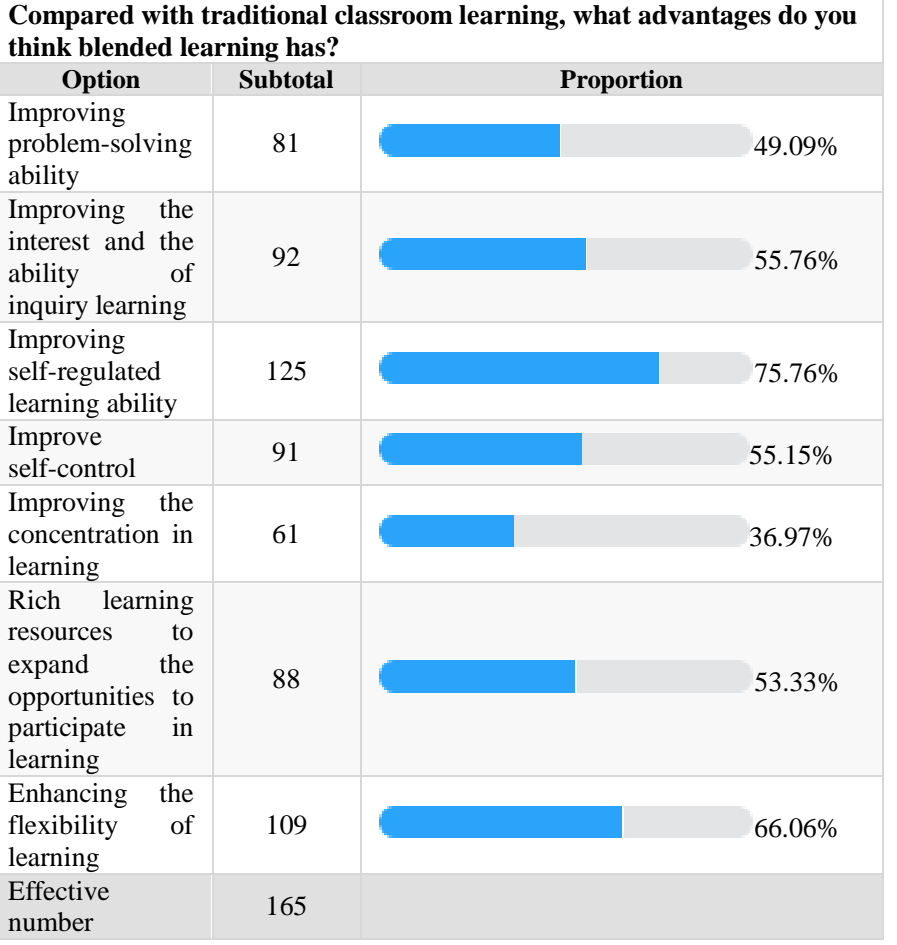

Table III is an analysis of the results of the advantages of blended learning. This topic is a multi-choice topic. 125 students, accounting for $76 \%$, think that blended learning can improve their autonomous learning ability. Secondly, 109 students, accounting for 66\%, think blended learning can enhance the flexibility of learning. The proportion of students who can improve their interest in learning and self-control is about 55\%. 88 students, accounting for 53\%, think blended learning can provide rich and comprehensive learning resources. The results show that blended learning can improve students' autonomous learning ability, enhance learning flexibility, and enhance learning interest and inquiry learning ability.

TABLE IV. ON EXTRACURRICULAR SELF-STUDY TIME

The course of Computer Application Basis adopts the blended learning mode, which requires students to carry out Extracurricular Autonomous Learning under the guidance of teachers. How long do you think is the most suitable time for extracurricular self-study per week?

\begin{tabular}{l|c|c|c|}
\multicolumn{1}{c|}{$\begin{array}{c}\text { Option } \\
\text { Within an hour }\end{array}$} & Subtotal & \multicolumn{2}{c}{ Proportion } \\
\hline \begin{tabular}{l|l|l}
$1-2$ hours \\
$2-3$ hours
\end{tabular} & 74 & & $13.94 \%$ \\
\hline $\begin{array}{l}\text { More than } 3 \\
\text { hours }\end{array}$ & 51 & & $44.85 \%$ \\
\hline $\begin{array}{l}\text { Effective } \\
\text { number }\end{array}$ & 17 & & $30.91 \%$ \\
\hline
\end{tabular}

Blended learning requires students to watch teaching videos in extra-curricular time, and to practice against teaching videos. In addition, the students whose learning tasks cannot be completed in class need to use their spare time to complete. The purpose of this survey is to find out the time of students' self-study after class every week so that teachers can arrange their learning tasks. Table IV analyses the results of the questionnaire. 74 students chose 1-2 hours, accounting for $45 \%$; 51 students answer 2-3 hours, accounting for 31\%; $14 \%$ students chose within 1 hour and $10 \%$ students answer more than 3 hours. It shows that the time of self-study after class should be controlled at about 2 hours per week. Teachers should arrange learning tasks accordingly so that most students can complete their learning tasks.

\section{CONCLUSION}

The development of Internet and information technology has changed the way and law of human learning. Blended learning, which combines information technology, Internet resources and education, is an important innovation and progress in education mode. Blended learning is not only a new way of learning, but also a new concept of learning. It has a significant and far-reaching impact on the current educational concepts, models and methods. Practice has proved that task-based blended learning mode has realized the transformation of teaching methods from "teaching" to "learning" and teaching objectives from "knowledge imparting" to "ability training". It mobilizes students' learning initiative and enthusiasm, stimulates students' interest in learning, and fully realizes students' individualized learning. It improves the teaching quality and effect of the course Computer Application Foundation, and provides a learning mode for informationization teaching.

\section{REFERENCES}

[1] Shichun Du, Zetian Fu. Blended Learning and Its Empirical Research Based on MOOC[J], China Educational Technology, 2016, (12):129-133

[2] Shuya Zhi, Sumei Gao. Practice and Exploration on Blended Learning Based on SPOC. [J]. Education Modernization, 2015 (12): 95-97. 
[3] Yi Jin, Yizhi Wang Junliang Liu. Hierarchical Instructional Design and Its Practice Based on the Blended Learning Theory [J].Modern Educational Technology, 2013(1):37-40

[4] Liu Rui, Haiyan Wang. The Design and Practice of "Flipped Classroom" Teaching Model Based on Micro-lesson [J].Modern Educational Technology, 2014, 24(5):26-32

[5] ShaoQing Guo, Yang Bin. Research on the Promotion of Flipped Classroom Teaching Strategies by Using Convergent
Evolution Micro Courses Instructional Design in University [J]. China Educational Technology, 2016(8):98-103

[6] Peng Su, Xiuhua Huang. The Exploration on Universities Promoting Practice of Blended Learning in the Perspective of the Learning Sciences[J].Modern Educational Technology, 2017, 27(10):61-66 